\title{
A single-case quasi-experimental design of Functional Analytic Psychotherapy for substance abuse
}

\author{
Alan S. Aranha ${ }^{1}$ \\ iD http://orcid.org/0000-0002-3230-6827 \\ Claudia K. B. Oshiro ${ }^{1}$ \\ (iD) http://orcid.org/000o-0001-8965-9124 \\ Elliot C. Wallace ${ }^{2}$ \\ iD http://orcid.org/0000-0002-2769-4108
}

\begin{abstract}
How to cite this article: Aranha, A. S., Oshiro, C. K. B., \& Wallace, E. C. (2020). A single-case quasi-experimental design of functional analytic psychotherapy for substance abuse. Psicologia: Teoria e Prática, 22(3), 263-286. doi:10.5935/1980-6906/psicologia.v22n3p263-286
\end{abstract}

Submission: 05/11/2019

Acceptance: 05/27/2020

1 University of São Paulo (USP), São Paulo, SP, Brazil.

2 University of Washington (UW), Seattle, Washington - DC, United States. 


\begin{abstract}
This study evaluated the effectiveness of Functional Analytic Psychotherapy (FAP) on clinically relevant behaviors (CRBs) in the context of substance abuse/chemical dependence and identifying the therapeutic components of change. The Functional Analytic Psychotherapy Rating Scale (FAPRS) was used to categorize therapist and client behaviors, and Timeline Followback was used to record drug abuse. Two participants were treated in a single case $A / A+B$ quasi-experimental design, in which $A=$ analytical-behavioral therapy and $A+B=$ FAP. The results showed that with the introduction of FAP, specifically the therapist's contingent responding to the participant's progress, there was a decrease in the use of substances after three months for both participants. The participant who spent more time in psychotherapy experienced greater benefits at follow-up and a larger reduction in drug use. We concluded that FAP altered CRBs by positively reinforcing progress in-session and was significantly correlated with improvement out-of-session.
\end{abstract}

Keywords: drug (dependency); behavior therapy; experimental design; drug rehabilitation; interpersonal relationships.

\title{
UM DELINEAMENTO QUASE-EXPERIMENTAL DE CASO ÚNICO DA PSICOTERAPIA ANALÍTICA FUNCIONAL PARA ABUSO DE SUBSTÂNCIAS
}

\begin{abstract}
Resumo
O objetivo da pesquisa foi avaliar o efeito da Psicoterapia Analítica Funcional (FAP) sobre os comportamentos clinicamente relevantes (CRBs) e abuso de substâncias de dependentes químicos e identificar os componentes terapêuticos de mudança. Foram utilizados os instrumentos Functional Analytic Psychotherapy Rating Scale para categorização de comportamentos do terapeuta e cliente e Timeline Followback para registrar o abuso de drogas. Dois participantes foram atendidos em um delineamento quase-experimental de caso único $A / A+B$, onde $A=$ Terapia AnalíticoComportamental e $A+B=F A P$. Os resultados indicaram que a introdução da FAP, em especial o responder contingente do terapeuta, acompanhou os progressos e houve melhora no consumo de substâncias após 3 meses para ambos. O participante que se manteve mais tempo em psicoterapia obteve maior benefício no follow-up e no consumo de drogas. Concluiu-se que a FAP alterou CRBs reforçando positivamente progressos em sessão e que isto provavelmente se correlacionou com melhoras extrassessão.
\end{abstract}

Palavras-chave: droga (dependência); terapia comportamental; delineamento experimental; reabilitação da droga; relações interpessoais. 


\title{
UN DISEÑO DE CASO ÚNICO CUASI EXPERIMENTAL DE PSICOTERAPIA ANALÍTICA FUNCIONAL PARA ABUSO DE SUSTANCIAS
}

\begin{abstract}
Resumen
El objetivo fue evaluar el efecto de la Psicoterapia Analítica Funcional (FAP) en los comportamientos clínicamente relevantes (clinically relevant behaviors - CRBs) e el abuso de sustancias de dependientes químicos, e identificar los componentes terapéuticos de cambio. Se utilizaron Functional Analytic Psychotherapy Rating Scale, para clasificar los comportamientos del terapeuta y del cliente, y timeline followback, para registrar el abuso. Dos participantes fueron evaluados a través de un diseño cuasiexperimental de caso único $A / A+B$, donde $A=$ terapia analítico-comportamental y $A+B=F A P$. Los resultados indicaron que la implementación de la respuesta contingente del terapeuta llevó a cambios en las CRBs y mejorías en el consumo de sustancias en los dos participantes después de tres meses de intervención. El participante que se mantuvo más tiempo en psicoterapia obtuvo mayor beneficio durante el seguimiento. Se concluye que FAP modificó las CRBs a través del reforzamiento positivo en sesión, lo que se relacionó con las mejoras fuera de sesión.

Palabras clave: drogas (dependencia); terapia conductista; delineamiento experimental; rehabilitación de la drogadicción; relaciones interpersonales.
\end{abstract}

\section{Introduction}

Behavior Analysis (BA) can be divided into three interrelated sub-areas. The first, Radical Behaviorism (BR), postures the philosophical aspects of this science, such as materialism, functionalism, and monism. Experimental Analysis of Behavior $(E A B)$ is considered basic research, in which a researcher manipulates environmental variables to understand how they influence behavior. And finally, Applied Behavior Analysis ( $A B A$ ) employs the concepts of basic research to intervene in humans problems. These three sub-areas are interconnected. $\mathrm{EAB}$ and $\mathrm{ABA}$ interpret data under the precepts of $R B$. The data of $E A B$ is used in new RB reflections and in the services provided by $A B A$. Results from interventions of $A B A$ strengthen or weaken assumptions of RB and bring more questions to be answered by $\mathrm{EAB}$ (Carvalho Neto, 2002).

Within ABA, behavioral-analytic psychotherapies are used to evaluate and intervene with verbal clients. Psychotherapies use functional analysis to identify 
how a client's behavioral deficits and excesses may have been constructed and how environmental variables maintained them over time. Behavioral intervention consists of manipulating the maintaining environmental variables to weaken the problem behaviors and, thus, build more effective behavioral repertoires (Tourinho \& Luna, 2010). One such behavioral psychotherapy, based in the philosophy of RB and the research method and concepts derived from $E A B$ and $A B A$, is the Functional Analytic Psychotherapy (FAP) (Kohlenberg \& Tsai, 1991).

\subsection{Functional analytic psychotherapy (FAP)}

Functional Analytical Psychotherapy's (FAP) goal is to improve the client's interpersonal relationships within their natural environment, which, behaviorally speaking, can be translated into the development of the interpersonal repertoire. The goal is to produce positive reinforcers and eliminate aversive social behavior. To achieve this, FAP utilizes stimulus generalization, stimulus control, and reinforcement processes. Proponents of this psychotherapy technique posit that problematic interpersonal response classes, which produce aversive stimulation and limit access to positive reinforcers, are generalized to the therapeutic relationship. These behaviors are exhibited in therapy since the psychotherapist is another person in the client's life. When problem behaviors occur in a therapy session, the professional has an opportunity to identify the maintaining variables, present antecedents that evoke behaviors of interest and present differential consequences of problem behaviors. Behavioral improvements are then expected to re-generalize into an out-of-session context (Kohlenberg \& Tsai, 1991).

FAP classifies three types of clinically relevant behaviors (CRB) that can occur in a psychotherapy session: CRB1 refers to client's problem behaviors occurring; CRB2 refers to client's behaviors that are indicative of therapeutic progress; and CRB3 are the client's verbal descriptions of their behavior and the controlling variables. The therapist's goal is to decrease the frequency of CRB1s and increase CRB2S and CRB3S - the latter help the generalization of in-session changes to out-of-session environments. Kohlenberg and Tsai (1991) describe five therapeutic guidelines for a FAP therapist to follow to achieve the goals of the psychotherapy: rule 1 establishes that the therapist should pay attention to client's CRBs during the session; rule 2 involves identifying antecedent events that evoke 
the occurrence of CRBs; rule 3, the proposed main mechanism of change, states that the therapist must respond contingently to the client's CRBs, such as reducing the frequency of CRB1s (punishment, extinction, blocking avoidance) and increasing CRB2s and CRBs3 (positive reinforcement); rule 4 involves the therapist evaluating the impact of their behavior on the client's repertoire; and rule 5 gives strategies for generalization outside of therapy.

Initially, FAP was developed to address intimacy and serious interpersonal problems, such as those found in Axis II of the Diagnostic and Statistical Manual of Mental Disorders (APA, 2013; Kohlenberg \& Tsai, 1991). Subsequently, these strategies began to be discussed and replicated in diverse types of psychiatric disorders, theoretical articles, case studies, and experimental research (Kanter et al., 2017). Two main types of experimental research in particular should be highlighted: group designs and single-subject designs.

\subsection{Experimental research and FAP}

In general, experimental research uses scientific methods to assist researchers in determining the effect of independent variable on the dependent variable, neutralizing or mitigating the effect of uncontrolled components that can interfere in the relationship between the independent and dependent variables. Most experiments have at least two conditions in which the dependent variable results are compared. By maintaining stability across all variables and manipulating the independent variable in the experimental condition, it is possible to compare its effect in relation to the control condition. If there is a measurable difference, researchers can, then, conclude that the manipulation of the independent variable was responsible for the change (Sidman, 1960). We highlight two important experimental designs: the group designs and single-subject designs.

In group designs, the effects of an experimental effects are evaluated by comparing two or more subject groups who receive different interventions. Participants who meet inclusion criteria are selected and randomly distributed between the control and experimental condition. The rationale for random distribution is to ensure that variations between individuals are mitigated. If participants were assigned to a condition in a non-random way and had characteristics in common the results of the dependent variables could be attributed to these characteristics, and not the intervention. During the experiment, each 
experimental group receives a brief intervention for an equal period of time. Then, data from each group are analyzed and compared. The between-groups design is widely used to determine the effectiveness of psychological interventions, but it has its limits in regards to understanding psychotherapy, as it does not allow for the assessment of the psychotherapeutic process, such as the regular changes that occur at each session and the identification of the mechanisms of clinical change involved (Kazdin, 2003).

In single-case designs, comparisons of the same subject are examined at different time points as opposed to few comparisons in several subjects, as in cross-subject designs. This design is also called "subject as its own control" or "n = 1" (Sidman, 1960). Kazdin (2003) describes three minimum specifications that a single-case design must meet in order to be able to infer causality between the independent variables and the dependent variables:

- Continuous assessment: the most important aspect of this design is that the dependent variables are recorded continuously, preferably before the intervention is introduced and while it is presented or removed. This makes it possible to infer the effect of the independent variable on the dependent variable and to implement the next requirement.

- Baseline: continuous evaluation allows the experimenter to know the level of the dependent variables before the intervention and to develop a hypothesis of how the data would respond if no treatment was applied. The baseline allows for visualization and comparison of the participant's repertoire before and after the administration of the independent variable.

- Stability: it is necessary that the dependent variables show stability in their tendency and variability, so that it is possible to contrast their changes after the introduction of independent variable. In order to draw conclusions about the effect of a psychotherapy, the target behavior rate must demonstrate a clear trend and maintain an average proportion at the baseline. This behavior should change, so that it is clear that the participant's behavioral pattern has been affected. The more stable the dependent variables are in the baseline, the easier it will be to infer the impact of the independent variables. 
FAP studies historically have a preference for single-subject experimental designs for two reasons: 1. given the analytic-behavioral tradition, researchers understand that data must come from comparing the same participant at different times and not between individuals; and 2. single-subject design prioritizes the description of the behavioral processes underlying the observed changes and allows the analysis of the therapeutic process over time.

\subsection{FAP and substance use disorders (SUD)}

Substance abuse and substance dependence are psychopathologies described in the fourth edition of the Diagnostic and Statistical Manual of Mental Disorders (APA) as a problematic pattern of substance use despite the adverse consequences that consumption brings to the user. A substance dependence diagnosis includes tolerance, withdrawal symptoms and a pattern of compulsive use, all of which are not found in an abuse diagnosis. The fifth edition of the manual (APA, 2013) unified the two cases into a single diagnosis of Substance Use Disorder (SUD). The new definition specifies issues involving psychoactive substances within a continuum of mild to more serious consequences. A diagnosis of SUD is more in line with the behavior analysis tradition, as both interpret psychopathologies as a set of behaviors in the individual's repertoire that lead to aversive consequences for themselves and for third parties (Tourinho \& Luna, 2010), modifying the division between abuse and dependency as arbitrary.

Researchers using a behavioral approach argue that drug use and the client's repertoire deficits can be conceptualized as learned behaviors. Substance abuse is maintained by pharmacological and social consequences, which can reinforce behavior positively or negatively (Higgins, Heil, \& Sigmon, 2007). The substance becomes relevant by providing temporary access to reinforcers, such as fun, friends, and the elimination of aversive events, that the individual would not be able to obtain otherwise. However, the contingencies cause serious problems in the long run. When trying to stop substance use, the users find themselves without the necessary skills to deal with increasingly intense difficulties, which leads them to relapse. The cycle of abuse does not confer the opportunity for emotional or behavioral development, and the cycle becomes self-perpetuating (Banaco \& Montan, 2018).

Behavioral therapists hold the rationale that new behaviors must be taught, so that clients can interact more effectively in their physical and social environment. 
Access to drug-free satisfaction, identification of factors that perpetuate consumption, and the development of problem-solving skills can end the SUD pattern and promote a healthier lifestyle (Higgins et al., 2007). Due to behavioral therapy's therapeutic achievements, it has been established that these techniques should be included effective treatment. Thus, there have been many variations of behavioral therapies proposed to treat SUD (Carroll \& Onken, 2005).

Despite advances in the field of psychology, only a minority of substance users receiving psychotherapy treatment achieve successful outcomes. This calls for the development of new psychotherapies and the adaptation of therapies that have already demonstrated being effective for other disorders. Understanding the active components of an intervention makes it possible to remove the expendable elements and maximize the therapeutic effect when applied to a new disorder (Carroll \& Onken, 2005). This is the case with the innovation of third-wave behavioral therapies, which have shown to be effective for several diagnoses and now are being used to treat SUD. One of these new approaches includes FAP (Kohlenberg \& Tsai, 1991).

FAP can be understood as an adjunct treatment that creates opportunities for the therapist to reinforce more effective interpersonal repertoires in-session, while conducting other interventions for SUD. The expectation is that the improved in-session repertoires will be generalized to out-of-session contexts, reducing the aversiveness of social events and enabling the client's contact with social and affective reinforcers (Holman et al., 2012), thus, decreasing the likelihood of relapses.

There are a few articles related FAP and SUD in the literature. Despite some interesting data, researchers are unable to demonstrate the primary effect of FAP on the performance of participants and a related reduction of drug use. As we will see, researchers do not use behavior analysis methods and apply different interventions using FAP.

Paul, Marx, and Orsillo (1999) presented a client with problems related to exhibitionism and marijuana abuse who was treated with Acceptance and Commitment Therapy (ACT) and FAP strategies. The case formulation revealed that marijuana use was sustained by predisposing exhibitionist behavior, because it reduced the aversiveness of its social consequences. The therapeutic goals were to accept exhibitionist thoughts and feelings, while reducing the frequency of exhibitionism and substance use and increasing social contact. The authors used 
self-report measures to record frequency and intensity of impulses, episodes of exposure, masturbation, and drug use. ACT strategies improved social competence, but marijuana use decreased only with the introduction of FAP. The hypothesis was that the reinforcement of CRB2S, exposed aversive content, facilitated the acceptance of aversive stimulation in session and, when generalized out of session, helped with the tolerance of urges to expose a precipitator of marijuana use. As for the study's limitations, there was no record of the client and therapist behaviors in session, thus, it was not possible to infer the direct effect of FAP on CRBs and the intervention mechanism of change.

Gifford et al. (2011) compared a medication intervention to medication with ACT and FAP therapy for cigarette smokers. Objective measurements were used for tobacco, and standardized inventories were used in order to identify psychiatric symptoms and behavioral processes. The results pointed to improvements after the intervention and sustained improvements in the one-year follow-up for the ACT/FAP group. Despite the randomized trial's great experimental control, it was not possible to define the effect of each therapy and to individually evaluate the mechanisms involved. Like the Paul et al. (1999) study, there was no record of the client and therapist behaviors in session.

Holman et al. (2012) conducted a study with five depressive and nicotine dependent clients who received a combination of Behavioral Activation, Smoking Cessation, ACT and FAP procedures. Self-report measures were acquired for depression and smoking, as well as objective measures for smoking. After the intervention, four clients experienced remission of the clinical criteria for major depression, and three were abstinent from tobacco - the other two had a significant decrease in consumption. Nevertheless, like the other two studies, the results did not allow for inference of the effect regarding each intervention type and the underlying change processes.

Indeed, previous research has employed FAP elements along with other behavioral therapies and presented promising results regarding the participant's drug use. However, the methodologies did not allow researchers to analyze the isolated effect of FAP and its mechanism of clinical change. The current study aims to exclusively evaluate the effectiveness of FAP and the essential components of change on the repertoire of clients with SUD as measured by CRBs and changes in the pattern of substance abuse. Our hypothesis was that the therapist's 
contingent responding would be responsible for decreases in the frequency of CRB1s and increases in CRB2s, which would lead to improvements in drug use after the intervention.

\section{Method}

\subsection{Participants}

The study was approved by the Ethical Research Committee, and it is registered under the Presentation Certificate of Ethical Appreciation (Certificado de Apresentação de Apreciação Ética [CAAE]) No. 45003515.2.0000.5561. Participants provided informed consent. The participants were two clients diagnosed with SUD who did not have any unstable medical and/or psychiatric conditions. Participant 1 , Rafael, was 63 years old and had originally sought out therapy for alcoholism. The identified CRB1s included client responses that were dismissive of the therapist's knowledge about him, such as superficial talk when relevant topics are evoked and extreme politeness when judging others. CRB2s included direct verbalizations of his behaviors/feelings and the contingencies that influenced him and giving opinions about people and events. Rafael started using Fluoxetine at 6omg in the third month of treatment. Participant 2, Lucas, was 36 years old and originally sought out treatment for cocaine/crack use. His CRB1s included deficits of analyzing contingencies of reinforcement that control his behavior and that affected third parties. Not understanding what affected him lead him to feelings of shame and depression (i.e., evaluating himself as "ignorant" for making a mistake). When he did not understand what influenced others, especially when someone denied a request, he got annoyed or upset (i.e., not understand why his wife doesn't want him to go out). The CRB2s included effectively relating to events involving other people (i.e., understanding the behavior of other people) and him (i.e., understanding his own behavior). When he arrived at the institution, he had been prescribed Fluoxetine at 20mg.

The researcher-therapist (the first author), who graduated six years ago, was a specialist in Clinical Psychology/Behavioral Therapy and had experience in private practice and institutions for the treatment of SUD. He was supervised in a therapy group coordinated by another psychologist (the second author) with 13 years of clinical experience, including expertise in conducting research and training in FAP. 
Table 2.1.1. Contingencies of reinforcement for participants' Rafael and Lucas CRBs.

\begin{tabular}{|c|c|c|c|}
\hline & Antecedent & Response & Consequence \\
\hline $\begin{array}{l}\text { Rafael's } \\
\text { CRB1 }\end{array}$ & $\begin{array}{l}\text { Therapist inquiries } \\
\text { about feelings/ } \\
\text { thoughts or evaluation } \\
\text { about others. }\end{array}$ & $\begin{array}{l}\text { Superficial talk and } \\
\text { extreme politeness. }\end{array}$ & $\begin{array}{l}\text { Therapist stops } \\
\text { questioning. }\end{array}$ \\
\hline $\begin{array}{l}\text { Rafael's } \\
\text { CRB2 }\end{array}$ & $\begin{array}{l}\text { Therapist inquiries } \\
\text { about feelings/ } \\
\text { thoughts or evaluation } \\
\text { about others. }\end{array}$ & $\begin{array}{l}\text { Verbalizations about his } \\
\text { behavior/feelings. } \\
\text { Opinions about people } \\
\text { and events. }\end{array}$ & $\begin{array}{l}\text { Therapist's social } \\
\text { reinforcement. }\end{array}$ \\
\hline $\begin{array}{l}\text { Lucas' } \\
\text { CRB1 }\end{array}$ & $\begin{array}{l}\text { Therapist inquiries } \\
\text { about an interpersonal } \\
\text { conflict. }\end{array}$ & $\begin{array}{l}\text { Deficits in analyzing } \\
\text { contingencies that } \\
\text { affected him and third } \\
\text { parties. } \\
\text { Ineffective social } \\
\text { response. }\end{array}$ & $\begin{array}{l}\text { No consequences } \\
\text { are provided and he } \\
\text { presented feelings } \\
\text { of sadness and } \\
\text { anger. }\end{array}$ \\
\hline $\begin{array}{l}\text { Lucas' } \\
\text { CRB2 }\end{array}$ & $\begin{array}{l}\text { Therapist inquiries } \\
\text { about an interpersonal } \\
\text { conflict. }\end{array}$ & $\begin{array}{l}\text { Effectively relating to } \\
\text { events about himself and } \\
\text { other people. } \\
\text { Effective social response. }\end{array}$ & $\begin{array}{l}\text { Therapist's social } \\
\text { reinforcement. }\end{array}$ \\
\hline
\end{tabular}

\subsection{Environment}

Data collection was performed in a specialized clinic for SUD, with a minimum voluntary hospitalization period of four months. Resocialization of the residents took place by phone contact (after seven days of hospitalization), family visits occurred on Saturdays and/or Sundays (after 15 days), and residents had the option to sleep in their residence on weekends (after 30 days). If they were not discharged after four months, the clients split their time between participating in the activities of the institution and looking for a job or professional courses. The treatment package included weekly medical appointments, SUD lectures, cognitive-behavioral psychoeducation, group psychoanalytic psychotherapy, alcoholics anonymous groups, group family counseling, and working out at an external gym. Individual psychotherapy sessions lasted between 50 and 60 minutes.

Participant 1, Rafael, spent eight months in the clinic, in which during the first four months he followed the rehabilitation rules and after the fifth month he 
alternated between the institution's psychotherapies and external activities during the week, such as buying newspapers, or going to a coffee shop, bakery and medical appointments. When a relapse occurred, the institution's clinical professionals decided how long it would be appropriate for Rafael to stay in detoxification without going out. Participant 2, Lucas, completed treatment two weeks ahead of schedule and adhered to rehabilitation standards, and he did not go out during weekdays.

\subsection{Measurement}

- Functional Analytic Psychotherapy Rating Scale (FAPRS) (Callaghan \& Follette, 2008): this scale is a system for coding client and therapist behavior in FAP sessions, transcribed from audio or video recordings, containing in its original version seven codes for the behavior of the client and 15 for the therapist. For the current study, client coding categories included codes for clinically relevant behaviors (CRB1, CRB2, and CRB3), problem or improvement in behaviors outside therapeutic relationship ( $\mathrm{O}_{1}$ and $\mathrm{O} 2$ ), talk that focuses on the therapeutic relationship (CTR) and general progression of the session (TPR). Therapist codes included observing CRBs (rule 1), evoking CRBs (rule 2), effectively responding to CRBs (rule $3-1$, rule $3-2$ ), asking about the effect of the intervention on the client's repertoire (rule 4), generalization strategies (rule 5), effectively responding to $\mathrm{O}_{1}$ and $\mathrm{O} 2$ (TO1 and TO2), general progression of the session (TPR), talk that focuses on the therapeutic relationship (TTR), and missing an opportunity to respond to CRBs or responding ineffectively (rule 3-INF). Codes are given to each turn of speech during the session, thus, after categorization it is possible to quantify the change in client behavior after the introduction or withdrawal of specific therapist behaviors.

- Timeline followback method (TLFB) (Sobell \& Sobell, 1994): The TLFB measures the frequency and intensity of the client's drug use before and after treatment. A record of the amount ingested is used for alcohol, while, for other drugs, only use or no-use is recorded, due to the difficulty of measuring the amount consumed. The TLFB can be administered in three formats: penciland-paper, interviewer or computer. In all modalities, an annual calendar is presented to the participant along with verbal aids about important dates and events (birthdays, vacations, holidays etc.), so that the participant can 
recall and report retrospectively their use each day before the treatment, in a period ranging from seven days to two years.

\subsection{Procedure}

We conducted a single case quasi-experimental design A/A + B (Kazdin, 2003), in which in the first phase (A) carried out case conceptualization and strategies of behavioral-analytic therapy (terapia analítico-comportamental [TAC]) (Tourinho \& Luna, 2010) regarding the analysis of external contingencies in the client's daily life. FAP $(A+B)$ was introduced after the CRBs were identified for each participant. In the second phase FAP was incorporated, focusing on evoking and reinforcing CRBs during sessions.

20 psychotherapy sessions were recorded and transcribed for the first participant, while 18 sessions were recorded and transcribed for the second participant. For each phase, five sessions were coded for each participant to establish single case standards for data collection as proposed by Kratochwill et al. (2013). Client 1's coded sessions were one, three, six, nine and 12 (phase A) and 13, 14, 15, 16 and 17 (phase $A+B$ ). Client 2's coded sessions were one, three, five, seven and ten (phase A), and 11, 12, 13, 14 and 15 (phase A + B). These data were chosen in order to evaluate $C R B$ from the first to the last session for phase $A$ and an ongoing assessment of FAP outcomes when the therapy was introduced in phase $A+B$ (the next five sessions). Three months after treatment, a follow-up session occurred in order to assess the progress sustained and a second TLFB application, which made it possible to compare drug consumption before and after the trial. Participant 1 stayed in the clinic in the period between A + B and follow-up. He continued his treatment and therapy processes. Participant 2 left the clinic and started therapy with another professional. He came to the clinic for the follow-up session.

The therapist-researcher conducted all FAPRS coding. A reliability assessment was carried out between the researcher and independent coders trained in the FAPRS. A session was randomly selected from each phase for each participant (sessions six and 16 for participant 1, and 5 and 15 for participant 2), which were then analyzed by 2 assessors, who also signed a TCLE before starting the process. Kratochwill et al. (2013) suggested $80 \%$ agreement or 0.6 Kappa to validate an observer's agreement. Both criteria were adopted in this study. First, the coder studied the FAPRS guide and case conceptualization for its client. After an individual 
meeting (30 minutes) with the researcher to present the conceptualization, a categorization practice was conducted with transcription and audio files from the sessions that were not previously assessed.

After the categorizations were sent, there was an hour-long meeting with the lead researcher, followed by two therapy sessions with the participants for a final assessment. The initial outcomes were not satisfied by the first coder (responsible for participant 1). After the first therapy session and with a new categorization, the first coder achieved an 82.31\% agreement and 0.74 Kappa (first therapy session) and 76\% agreement and 0.64 Kappa (second therapy session). The second coder (in charge of participant 2) also did not present sufficient indexes, therefore, it was not possible to calculate Kappa, due to the differences found in the number of categories that were used by the lead researcher (13) and the assessor (7). Additionally, there were categories with low occurrences in session (only one or two), which decreased the agreement probability. Thus, a new coding scheme was carried out to make possible to calculate Kappa. In the third attempt, the results were $82.97 \%$ agreement and 0.74 Kappa (first therapy session) and $76.19 \%$ agreement (second therapy session). It was not possible to calculate Kappa for the second session due to the differences in the number of categories.

As was previously argued by Villas Bôas (2015), the time available for agreement assessment could affect the data analysis. Training can take up to 100 hours according to some studies, which was not feasible for this work. The main challenges faced by the independent assessors were to understand FAPRS guide (change categories such as rule 1 and rule 2 and TTR and TPR), and not an unawareness of the cases, which could both be addressed with sufficient training time. Thus, the indexes that scored below the established criteria were classified as reasonably satisfactory. For data analysis, the lead researcher calculated the percentage of occurrences for each category code, in order to compare sessions even if they had a different total number of verbalizations. All data were analyzed through visual inspection (Kazdin, 2003; Kratochwill et al., 2013; Sidman, 1960).

\section{Results and discussion}

Figure 3.1 presents the CRB1S and CRB2s of both participants during the treatment phases and the follow-up sessions. This shows that the introduction of FAP led to a lower frequency of CRB1s and a higher frequency of CRB2s for both 
participants. While the positive results remained stable until the end of sessions, CRB1s had different results for each client. During the FAP sessions, participant 1's CRB1s decreased (top panel), but this trend began in phase $A$, which raises questions concerning causality. Changes in magnitude (session $12=11.91 \%$; session $13=$ $3.47 \%$ ) and changes in stability were considered a FAP effect. In contrast, participant 2's CRBs were not suddenly altered by FAP.I fact, the percentage after FAP was equivalent to that of session 12 during phase A (9.42\%). Similar to what was proposed by Villas Bôas (2015), we hypothesized that the difference found could be explained by the nature of the CRBs. The therapist focused on a specific repertoire of establishing more effective verbal relations about events, which could not be done in only one therapy session. Thus, it was necessary for the client to express several relations and the therapist to reinforce the desired relations. Our hypothesis was corroborated by the CRBs that increased in this session (11.23\%), the best result in this phase. Simões (2014) described a similar phenomenon, which evaluated the impact of metaphors on the client's verbal relations about events. Such changes happen only in latter stages after the independent variable has been introduced. 

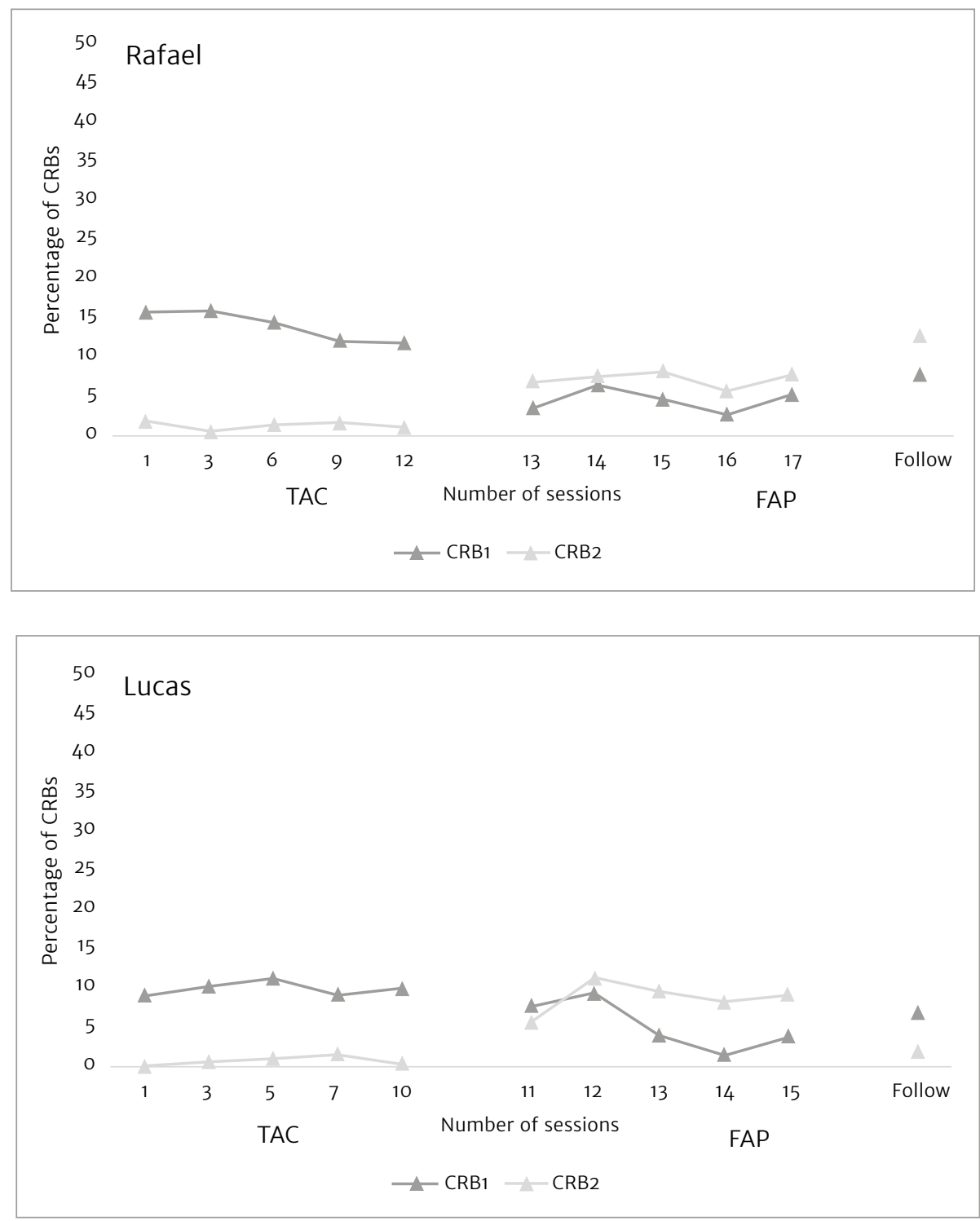

Figure 3.1. Percentage of CRB1S and CRB2S (problem behaviors and therapeutic progress) over ten sessions of psychotherapy for Rafael (upper panel) and Lucas (lower panel), analyzed according to experimental phases $A$ $=$ TAC and $A+B=$ FAP and in the follow-up session. 
Follow-up results for participant 1 , who continued the treatment in group and individual sessions, suggest that therapeutic progress continued ( $C R B 1=7.87 \%$ and $\mathrm{CRB} 2=12.82 \%)$. It could be argued that the continuity of the treatment contributed to the improvements in CRB2S, in addition to the increase in CRB1s when compared with session 17. A session analysis revealed that some of the behaviors that could be classified as CRB1S (1.74\%) varied in quality once the client openly stated that he "would not like to talk about a certain matter" instead of being quiet or briefly speaking about it. Such a result revealed even more improvement.

Participant 2's results were not the same. He did not finish the 20 planned sessions, and only attended 18 . He did not keep in touch with the researchers and started a different psychotherapy with another professional. The follow-up session revealed that his CRB1s remained the same (4.66\%) and CRB2s were the same as before the intervention (1.69\%). It is possible that the short period of time did not allow the CRB2s to be established and generalized to out-of-session relationships (the early termination was motivated by a problem behavior). The CRB1s could be explained by the fact that the therapist focused on managing relapses, which decreased the verbalizations about relations between interpersonal events. Even in smaller proportions, the CRB1s which were analyzed evoked the same relationship challenges that can raise the probability of drug use.

The results of this study can be seen as a systematic replication (Sidman, 1960) of previous studies, including quasi-experimental designs (Villas Bôas, 2015), single case reversion experimental designs (Geremias, 2014), and multiple baseline between participants designs (Lima, 2017). In the current study, during the FAP therapy sessions there was a decrease in CRB1s and an increase in CRB2s. Replication of this finding across the two clients also strengthened the hypothesis that the same active principle most likely influenced the repertoires of both participants. 

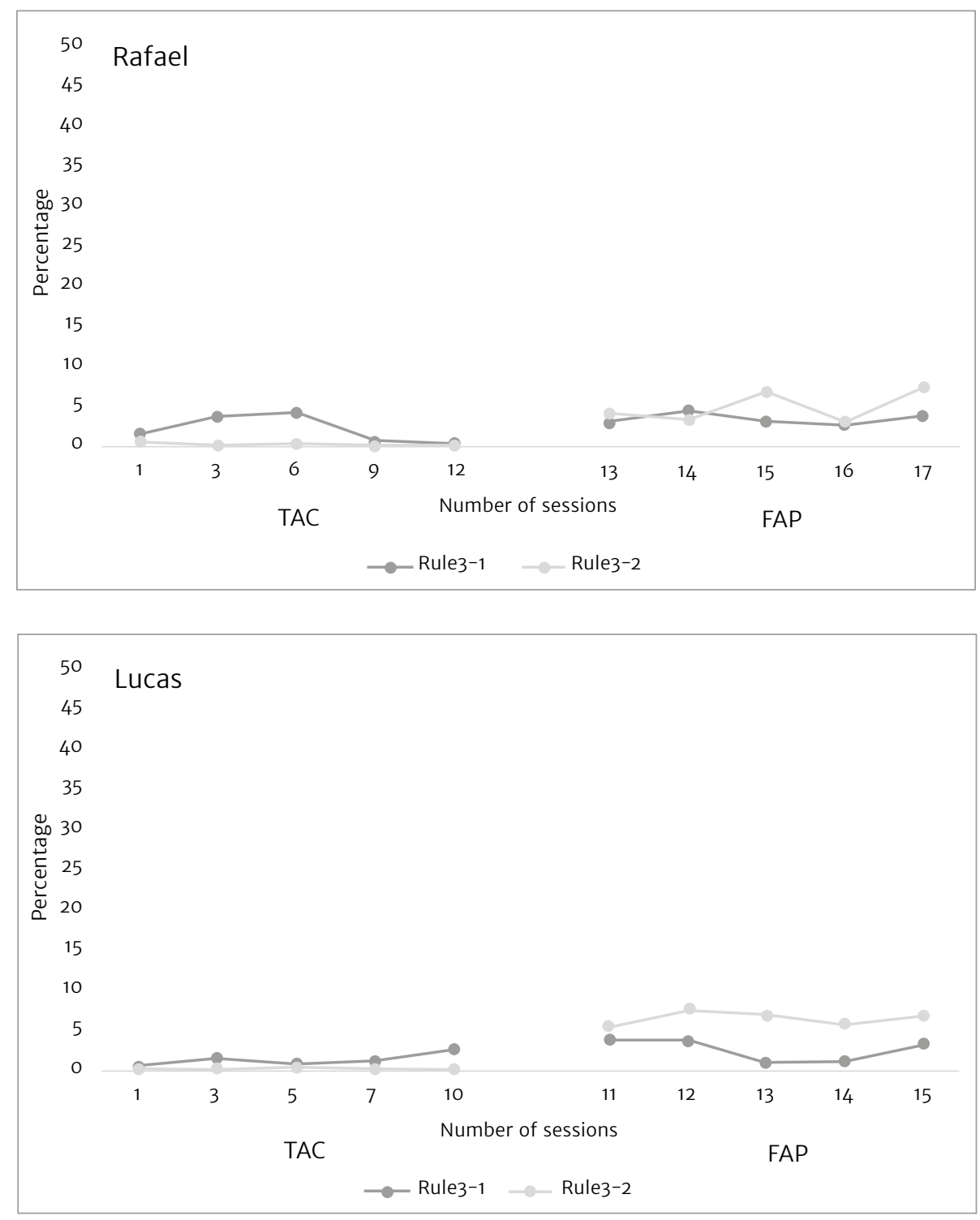

Figure 3.2. Percentage of rules 3-1 and rules 3-2 (respond effectively to CRB1s and CRB2s) over ten sessions of psychotherapy for Rafael (upper panel) and Lucas (lower panel), analyzed according to experimental phases $A=T A C$ and $A+B=F A P$. 
Figure 3.2 shows the percentage of effective therapist responses to CRB1S and CRB2s. Rules 3-1 oscillated for both participants during phase $A$, and then increased and remained the same in phase $A+B$. Therefore, the therapist's intervention did not influence the frequency of client behaviors. Although, adding rule 3-2 during the second stage reversed the proportions of CRBs. Rule 3-2 was observed at higher rates when compared to rule $3^{-1}$ in all sessions of phase $A+B$, except for participant $1^{\prime}$ 's $14^{\text {th }}$ session (rule $3-1=4.36 \%$ and rule $3-2=3.27 \%$ ). Despite the therapist focusing on responding to CRB1s during $14^{\text {th }}$ session, CRB2S occurred more frequently.

These data contribute to previous FAP studies regarding the effectiveness of FAP and the therapeutic progress. In highly controlled designs, despite variations in the proportion of rules 3-1 in FAP and no-FAP phases (Geremias, 2014), rule 3-2 occurred more frequently in FAP therapy sessions and was related to a decrease in CRB1s and an increase in CRB2s (Kanter et al., 2017). This suggests that the mechanism of clinical change in this psychotherapy is the therapist's contingent response to the client's improvements rather than problems.

Additionally, Figure 3.3 presents data on drug abuse among participants. Before the intervention, participant 1 drank daily, with greater frequency during the week (average of 12 doses) and lower frequency at weekends (average of three doses). He began the first treatment (without resocialization) and did not drink, but when he finished, he drank during the next two days (four and five doses). Data was collected in the second institution where he was hospitalized. A relapse not recorded by TLFB occurred in the week of session 18 and he was instructed not to leave the clinic for 15 days. On the third day of external activities, he had a second relapse (five doses) and was suspended for another 15 days. After this hiatus it was determined by the technical team that the client could perform his external activities even if there were relapses. One week later he had a new relapse (eight doses) and two months later, the last relapse was recorded (three doses).

Participant 2 previously consumed cocaine/crack during the weekdays but on weekends was able to control himself and spend time with his family. However, after three consecutive weekends using crack and with the perception that he had lost control, he sought out the institution. When he was hospitalized, he stayed for one month without using drugs, started again a few times a week and, then, in an attempt to prevent relapses, began using every 15 days on average. 

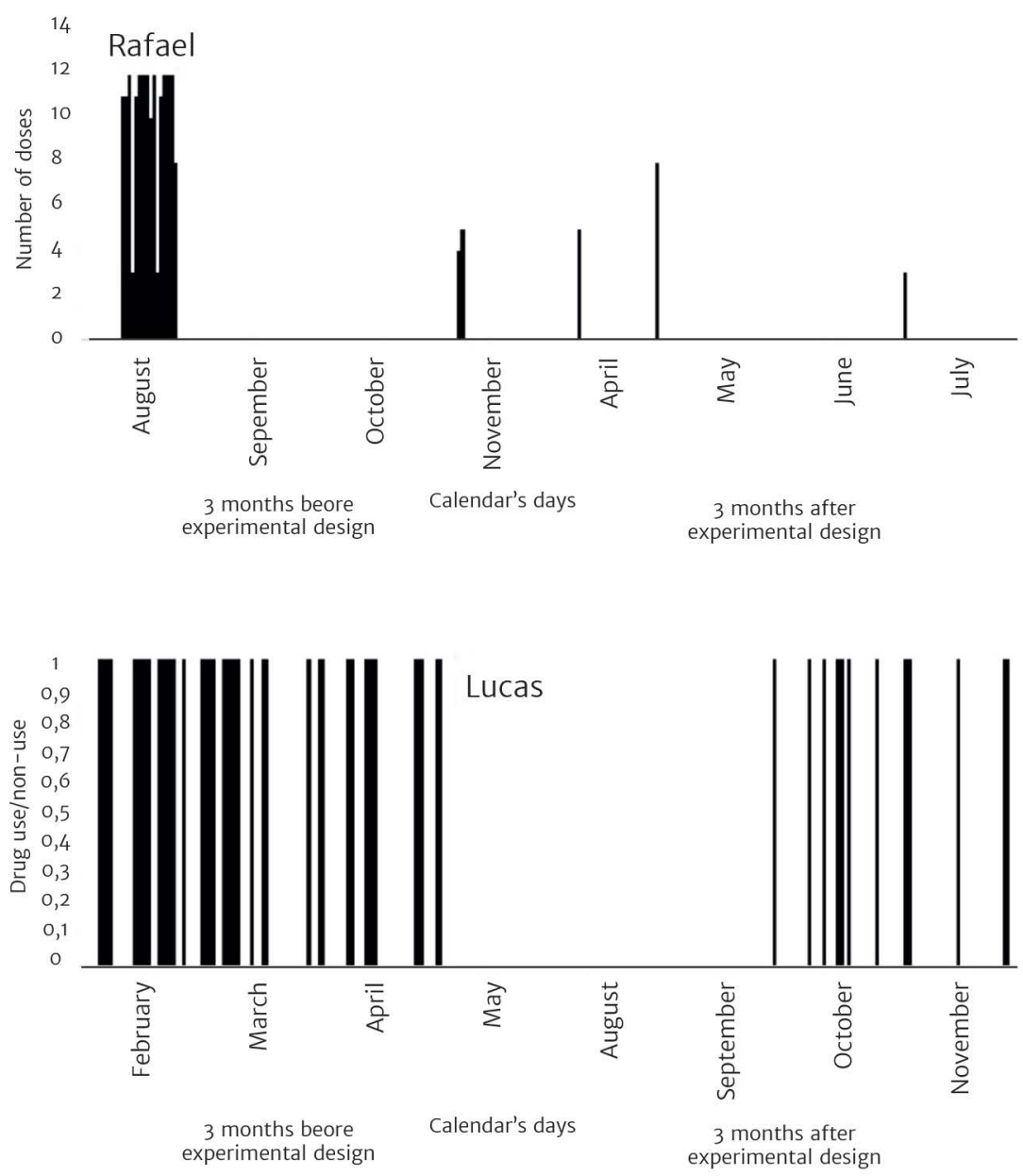

Figure 3.3. Consumption of psychoactive substance three months before and three months after the quasi-experimental design. Rafael (upper panel) reported alcohol (doses) and Lucas (lower panel), cocaine/crack (use and non-use).

Both clients showed quantitative improvements in drug use, and a qualitative analysis revealed a bigger improvement for Rafael and a smaller one for Lucas. Participant 1 started a romantic relationship, improved his dialogue with the clinic 
professionals, and his CRB2s were more improved on the follow-up session. Probably, the established repertoire and positive reinforcements that he had practiced helped him to consume less alcohol. On the other hand, participant 2 left the facility before the planned date and did not show the same progress at the follow-up session. Furthermore, participant 2 suffered a sports injury during his first month out of the institution, which obligated him to stay at home with his wife and led to more interpersonal conflicts. His drug use as per the TLFB followed the rate of positive reinforcers he had access to (during the first month) and increased with the exposure to negative reinforcers (the second and third months). If the progress went as expected (improved CRB2s generalized to relationships out of sessions), he might have experienced fewer conflicts and his crack use might have decreased.

We can identify three main limitations to this work. The first concerns the chosen method. The quasi-experimental design revealed a correlation between the independent variable and the dependent variable, but we cannot be sure about this relationship. It is necessary to use more powerful designs that would allow researchers to measure the influence of FAP on CRBs and participants' drug use. We suggest a reversion design or multiple baseline (Kazdin, 2003; Kratochwill et al., 2013). Despite the relative success with the agreement assessment compared to the training time, we question if the results could have been better if the assessor had a better understanding of the FAPRS. We recommend a longer training time (Kratochwill et al., 2013), which could then improve the study's internal validity. Finally, the record of drug use does not allow for an establishment of a clear relation between FAP and drug use. Thus, we suggest that a more objective measure (for instance, urine tests) and daily/weekly (instead of pre and post-test) measures allow for a more effective evaluation of how CRB changes increase or decrease in drug use.

\section{Final remarks}

Previous studies of FAP and SUD have demonstrated improvements in participants' behavioral repertoire and drug use. Nevertheless, they do not specifically point out to individual effects of FAP and its mechanism of change. This quasi-experimental design made it possible to assess the impact of FAP, and to identify changes in the interpersonal repertoire for both participants, which resulted 
from the therapist's contingent responding to behavioral improvements. However, the data shows that participant 1, who had a longer intervention process, had better outcomes from therapy. Future researchers should apply single-case designs with more precision, sufficient training time for agreement assessor, and more straightforward and continuous measures to assess drug consumption.

\section{References}

American Psychiatric Association. (2013). Diagnostic and statistical manual of mental disorders (5th ed.). Washington: American Psychiatric Association. doi:10.1176/appi. books. 9780890425596

Banaco, R. A., \& Montan, R. N. M. (2018). Terapia analítico-comportamental. In N. A. Zanelatto, \& R. Laranjeira (Orgs.). O tratamento da dependência química e as terapias cognitivo-comportamentais: Um guia para terapeutas (2nd ed.) (pp. 115-132). Porto Alegre: Artmed.

Callaghan, G. M., \& Follette, W. C. (2008). FAPRS manual: Manual for the functional analytic psychotherapy rating scale. The Behavior Analyst Today, 9(1), 57-97 doi:10.1037/ho100648

Carroll, K. M., \& Onken, L. S. (2005). Behavioral therapies for drug abuse. The American Journal of Psychiatry, 168(8), 1452-1460 doi:10.1176/appi.ajp.162.8.1452

Carvalho Neto, M. B. (2002). Análise do comportamento: Behaviorismo radical, análise experimental do comportamento e análise aplicada do comportamento. Interação em Psicologia, 6(1), 13-18. doi:10.5380/psi.v6i1.3188

Gifford, E. V., Kohlenberg, B. S., Hayes, S. C., Pierson H. M., Piasecki, M. P., Antonnucio, D. O., \& Palm, K. M. (2011). Does acceptance and relationship focused behavior therapy contribute to bupropion outcomes? A randomized controlled trial of functional analytic psychotherapy and acceptance and commitment therapy for smoking cessation. Behavior Therapy, 42, 700-715. doi:10.1016/j.beth.2011.03.002

Geremias, M. C. G. (2014). Manejo de esquivas emocionais na psicoterapia analítica funcional: Delineamento experimental de caso único. (Unpublished Master's thesis). Universidade de São Paulo, São Paulo. doi:10.11606/D.47.2014.tde-17032015150030

Higgins, S. T., Heil, S. H., \& Sigmon, S. C. (2007). A behavioral approach to the treatment of substance use disorders. In P. Sturmey (Ed.), Functional analysis in clinical treatment (pp. 261-282). Burlington: Elsevier. doi:10.1016/B978-012372544-8/50015-X 
Holman, G., Kohlenberg, R. J., Tsai, M., Haworth, K., Jacobson, E., \& Liu, S. (2012). Functional analytic psychotherapy is a framework for implementing evidencebased practices: The example of integrated smoking cessation and depression treatment. International Journal of Behavioral Consultation and Therapy, 7, 58-62. doi:10.1037/ho100938

Kanter, J. W., Manbeck, K., Kuczynski, A. M., Maitland, D. W. M., Villas Bôas, A., \& Reyes, M. (2017). A comprehensive review of research on Functional Analytic Psychotherapy. Clinical Psychology Review, 58, 141-156. doi:10.1016/j.cpr.2017.09.01012

Kazdin, A. E. (2003). Research design in clinical psychology (4th ed.). Needham Heights: Ally \& Bacon.

Kohlenberg, R. J., \& Tsai, M. (1991). Functional analytic psychotherapy: A guide for creating intense and curative therapeutic relationships. New York: Plenum. doi:10.1007/ $978-0-387-70855-3$

Kratochwill, T. R., Hitchcock, J. H., Horner, R. H., Levin, J. R., Odom, S. L., Rindskopf, D. M., \& Shadish, W. R. (2013). Single-case intervention research design standards. Remedial and Special Education, 34(1), 26-38. doi:10.1177/0741932512452794

Lima, G. O. (2017). Psicoterapia analítica funcional como tratamento do transtorno de estresse pós-traumático: Delineamento experimental de caso único. (Unpublished Master's thesis). Universidade de São Paulo, São Paulo. doi:10.11606/D.47.2018.tde06022018-162328

Paul, R. H., Marx, B. P., \& Orsillo, S. M. (1999). Acceptance-based psychotherapy in the treatment of an adjudicated exhibitionist: A case example. Behavior Therapy, 30, 149-162. doi:10.1016/S0005-7894(99)80051-3

Sidman, M. (1960). Tactics of scientific research: Evaluating experimental data in psychology. New York: Basic Books.

Simões, E. F. (2014). Manejo de metáforas em psicoterapia analítico-comportamental. (Unpublished Master's thesis). Universidade de São Paulo, São Paulo. doi: 10.11606/D.47.2014.tde-17032015-152454

Sobell, L. C., \& Sobell, M. B. (1994). Timeline followback (TLFB) user's manual. Toronto: Addiction Research Foundation.

Tourinho, E. Z., \& Luna, S. V. (Orgs.). (2010). Análise do comportamento: Investigações históricas, conceituais e aplicadas. São Paulo: Roca. 
Villas Bôas, A. (2015). Efeitos de análises de contingências sobre comportamentos clinicamente relevantes e sobre mudanças extra sessão. (Unpublished Doctoral dissertation). Universidade de São Paulo, São Paulo. doi:10.11606/T.47.2015.tde-24092015154310

\section{Authors notes}

Alan S. Aranha, Department of Clinical Psychology (PSC), University of São Paulo (USP); Claudia K. B. Oshiro, Department of Clinical Psychology (PSC), University of São Paulo (USP); Elliot C. Wallace, Center for the Science of Social Connection, Center for the Study of Health and Risk Behavior (CSSC/CSHR), University of Washington School of Medicine (UW).

Correspondence concerning this article should be addressed to Alan Souza Aranha, Avenida Prof. Mello Moraes, 1721, Butantã, Cidade Universitária, São Paulo, SP. CEP 05508-030.

E-mail: alansaranha@gmail.com 